Review

\title{
Microbiological, technological and therapeutic properties of kefir: a natural probiotic beverage
}

\author{
Analy Machado de Oliveira Leite ${ }^{1}$, Marco Antonio Lemos Miguel ${ }^{2}$, \\ Raquel Silva Peixoto ${ }^{2}$, Alexandre Soares Rosado ${ }^{2}$, Joab Trajano Silva ${ }^{1}$, \\ Vania Margaret Flosi Paschoalin ${ }^{1}$ \\ ${ }^{1}$ Instituto de Química, Universidade Federal do Rio de Janeiro, Cidade Universitária \\ Rio de Janeiro, RJ, Brazil. \\ ${ }^{2}$ Instituto de Microbiologia, Universidade Federal do Rio de Janeiro, Cidade Universitária, \\ Rio de Janeiro, RJ, Brazil.
}

Submitted: June 21, 2012; Approved: September 10, 2012.

\begin{abstract}
Kefir is a fermented milk beverage produced by the action of bacteria and yeasts that exist in symbiotic association in kefir grains. The artisanal production of the kefir is based on the tradition of the peoples of Caucasus, which has spread to other parts of the world, from the late $19^{\text {th }}$ century, and nowadays integrates its nutritional and therapeutic indications to the everyday food choices of several populations. The large number of microorganisms present in kefir and their microbial interactions, the possible bioactive compounds resulting of microbial metabolism, and the benefits associated with the use this beverage confers kefir the status of a natural probiotic, designated as the $21^{\text {th }}$ century yoghurt. Several studies have shown that kefir and its constituents have antimicrobial, antitumor, anticarcinogenic and immunomodulatory activity and also improve lactose digestion, among others. This review includes data on the technological aspects, the main beneficial effects on human health of kefir and its microbiological composition. Generally, kefir grains contain a relatively stable and specific microbiota enclosed in a matrix of polysaccharides and proteins. Microbial interactions in kefir are complex due to the composition of kefir grains, which seems to differ among different studies, although some predominant Lactobacillus species are always present. Besides, the specific populations of individual grains seem to contribute to the particular sensory characteristics present in fermented beverages. This review also includes new electron microscopy data on the distribution of microorganisms within different Brazilian kefir grains, which showed a relative change in its distribution according to grain origin.
\end{abstract}

Key words: probiotic, microbial diversity, kefir grains, fermented milk, kefir.

\section{Introduction}

The word kefir is derived from the Turkish word keyif, which means "feeling good" after its ingestion (Lopitz-Otsoa et al., 2006; Tamime, 2006). The kefir beverage is originally from the Caucasus Mountains, a traditional product highly consumed in Eastern Europe, Russia and Southwest Asia (Tamime, 2006). Currently, an increase in kefir consumption in many countries has been reported, due to its unique sensory properties and long history associated with beneficial effects on human health (Farnworth, 2005; Otles and Cagindi, 2003; Tamime, 2006). In Brazil, the knowledge of this beverage, as well as the benefits of the inclusion of probiotic food in a regular diet, are not very widespread, and kefir manufacturing is exclusively artisanal (Carneiro, 2010; Magalhães et al., 2010a).

Kefir is characterized by its distinct flavour, typical of yeast, and an effervescent effect felt in the mouth (Lopitz-Otsoa et al., 2006; Rattray and O'Connel, 2011). The 
main products of kefir fermentation are lactic acid, ethanol and $\mathrm{CO}_{2}$, which confer this beverage viscosity, acidity and low alcohol content. Minor components can also be found, including diacetyl, acetaldehyde, ethyl and amino acids contributing to the flavour composition (Rattray and O'Connel, 2011). This drink differs from other fermented dairy products because it is not the result of the metabolic activity of a single or a few microbial species (Farnworth and Mainville, 2008).

\section{Kefir Grains}

Kefir grains play a natural starter culture role during the production of kefir and are recovered after the fermentation process by milk straining (Rattray and O'Connel, 2011). These grains are composed of microorganisms immobilized on a polysaccharide and protein matrix, where several species of bacteria and yeast coexist in symbiotic association (Farnworth and Mainville, 2008; Garrote et al., 2010). In this ecosystem there is a relatively stable microorganism population, which interacts with and influences other members of the community. This population provides the synthesis of bioactive metabolites, which are essential for grain growth and microorganism inhibition, such as food pathogens and contaminants (Garrote et al., 2010).

Kefir grains vary in size, from 0.3 to $3.0 \mathrm{~cm}$ in diameter (Figure 1), are characterized by an irregular, multilobular surface, united by a single central section, and their color varies from white to yellowish white. The grains are elastic and have a viscous and firm texture (Farnworth and Mainville, 2008; Magalhães et al., 2011; Rea et al., 1996).

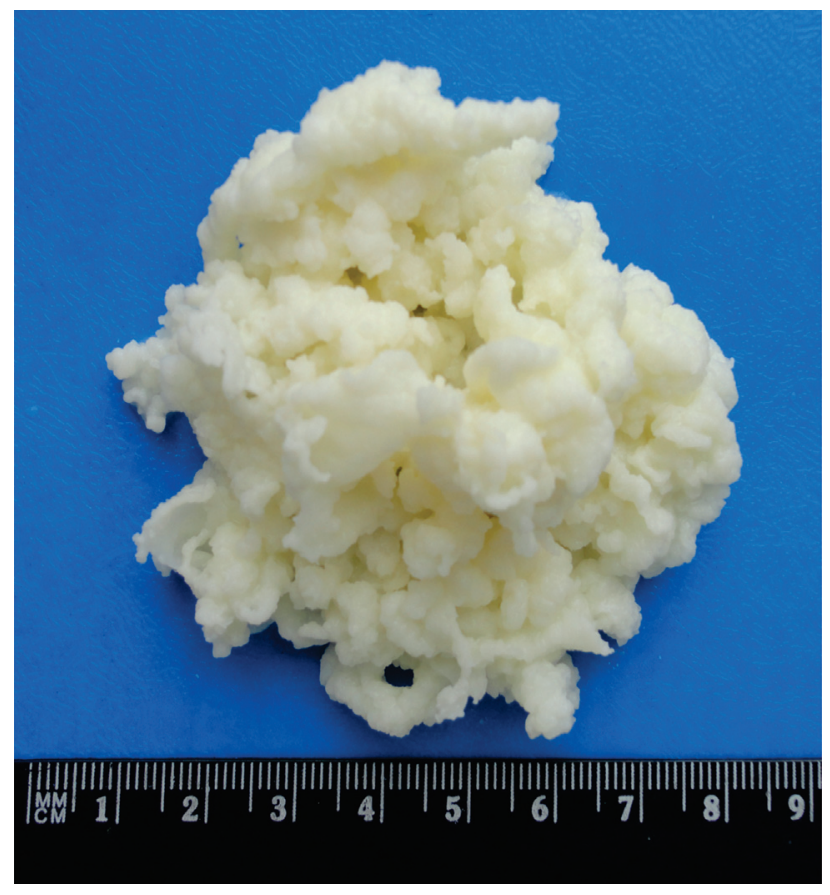

Figure 1 - Macroscopic structure of kefir grains.
Although the kefir drink can be found in many countries, in Brazil the grains are not available commercially, and are culturally donated from person to person.

\section{Microbiological Aspects}

In kefir, lactic acid bacteria (LAB) are primarily responsible for the conversion of the lactose present in milk into lactic acid, which results in a $\mathrm{pH}$ decrease and milk preservation. Other kefir microbial constituents include lactose-fermenting yeasts that produce ethanol and $\mathrm{CO}_{2}$. Non-lactose fermenting yeast and acetic acid bacteria (AAB) also participate in the process (Magalhães et al., 2011; Rattray and O'Connel, 2011). After fermentation the grains increase in about $5-7 \%$ of their biomass. During their growth in milk, the microorganism proportions in the grains differ from those present in the final product (Rattray and O'Connel, 2011; Tamime, 2006). This difference is associated with the fermentation process conditions such as fermentation time, temperature, degree of agitation, type of milk, grain/milk inoculum ratio and microorganism distribution, among others (Rattray and O'Connel, 2011; Simova et al., 2002; Tamime, 2006).

Traditionally, classical microbiological methods are used to study kefir microbiota (Rea et al., 1996; Simova et al., 2002). While these methods are useful, in some cases they are not discriminating enough to identify closely related or new species. Because of the microbial symbiotic association present in the grains, the growth and survival of individual strains are dependent on the presence of each other. Often, when microorganisms are isolated from the grains, they do not grow well in milk and/or show reduced biochemical activity (Farnworth and Mainville, 2008). Therefore, independent cultivation methods have been used as a complement to conventional methods in the study of kefir grain microbiota. The polymerase chain reaction technique, coupled to electrophoresis in denaturing gradient gel (PCR-DGGE) has proved appropriate for analyzing complex microbial consortia (Jianzhong et al., 2009; Leite et al., 2012; Magalhães et al., 2010a, 2010b), while the partial sequencing of the gene coding for $16 \mathrm{~S}$ rRNA has been used for species identification (Mainville et al., 2006; Rattray and O'Connel, 2011). However, some studies show that the PCR-DGGE technique does not allow the detection of significant changes during kefir fermentation (Magalhães et al., 2010a), probably due to the relative stability of the dominant population in this community.

The complexity of this community can be better understood by the introduction of massive sequencing techniques, such as pyrosequencing. Two recent studies, one conducted by our research group (Dobson et al., 2011; Leite et al., 2012) used this technique to evaluate kefir microbial diversity and detected the presence of microorganisms belonging to minority groups, not previously reported, by dependent or independent culture techniques. Furthermore, Leite et al. (2012), comparing three Brazilian kefir 
grains, reported that, although of different origins of grains, certain microorganism groups such as Lactobacillus species were always present in all grains. The authors suggest that the minority and specific populations of individual grains can contribute to the particular sensory characteristics present in fermented beverages (Leite et al., 2012).

Some species rarely isolated from kefir grains and the kefir beverage are not key species, and are usually considered contaminants. Recently, the fungi Dipodascus capitus and Trichosporon coremiiforme, considered pathogens, were identified by gene sequencing in kefir grains (Rattray and O'Connel, 2011). Some bacterial contaminants have also been described, such as Pseudomonas spp. (Dobson et al., 2011; Jianzhong et al., 2009; Leite et al., 2012) and members of the Enterobacteriaceae (Dobson et al., 2011) and Clostridiaceae (Dobson et al., 2011) families, when kefir grain microbiota was characterized by pyrosequencing and PCR-DGGE. The presence of these microorganisms may be associated with contamination during handling of kefir grains or improper practices adopted during the preparation of the kefir beverage.

\section{Microorganism Distribution in Kefir Grains}

The distribution of microorganisms inside kefir grains has been studied, and results are controversial. A group of researchers supports the hypothesis that yeasts are generally found in the inner and intermediate grain zone, with rod-shaped bacteria and rare lactococci predominantly on the surface area (Bottazzi and Bianchi, 1980; Lin et al., 1999). Conversely, other researchers (Guzel-Seydim et al., 2005; Jianzhong et al., 2009; Magalhães et al., 2011; Rea et al., 1996) describe that yeasts are distributed in both the outer and the inner grain areas, with the main difference between the two areas being related to rod-shaped bacteria morphology. Contrary to previously reported results (Bottazzi and Bianchi, 1980; Rea et al., 1996), Guzel-Seydim et al. (2005) observed a predominance of rod-shaped bacteria, without any evidence of yeast in the inner grain area. Furthermore, some authors (Jianzhong et al., 2009; Magalhães et al., 2011) have reported a lower number of cells observed in the inner grain portion as compared with the outer portion. Some authors have postulated that fibrillar material observed in the grain may be in fact the polysaccharide kefiran present throughout the grain (Guzel-Seydim et al., 2005; Magalhães et al., 2010a, 2010b, 2011).

Our research group also evaluated the distribution of microorganisms from three Brazilian kefir grains (Figure 2) and observed a relative variation in their distribution according to grain origin. In general, rod-shaped bacteria were observed both in the inner (Figure $2 \mathrm{~b}, \mathrm{~d}, \mathrm{f}$ ) and the outer grain portions (Figure $2 \mathrm{a}, \mathrm{c}, \mathrm{e}$ ), whereas yeasts were most frequent in the outer portion (Figure $2 \mathrm{a}, \mathrm{c}, \mathrm{e}$ ). Cocci were observed in the outer portion of one of the grains. In all probability, the granular material observed corresponded to particles of coagulated milk adhered to the sur- face of the grain and the fibrillar material to the polysaccharide kefiran, spread over all parts of the grains (Guzel-Seydim et al., 2005; Magalhães et al., 2011; Rea et al., 1996).

Although L. lactis is one of the predominant microorganisms isolated from the kefir drink, several investigators (Guzel-Seydim et al., 2005; Jianzhong et al., 2009; Magalhães et al., 2011) have not observed cocci in micrographs, probably due to poor lactococcal adhesion to the grains during growth, which would facilitate lactococcal release in the washing process (Guzel-Seydim et al., 2005; Jianzhong et al., 2009; Magalhães et al., 2011; Rea et al., 1996). Furthermore, it is likely that the acidic $\mathrm{pH}$ in the grain interior would interfere in the growth of this microorganism in this particular microenvironment (Rea et al., 1996).

It is probable that surface microorganisms cause a greater impact on the kefir fermentation process (Farnworth and Mainville, 2008). However, studies have shown that a wide variation in microbial population occurs between different grains and within the same grain. Lin et al. (1999) concluded that grain origin site alone can explain the differences that have been reported in several studies by electron microscopy.

\section{Kefir Bacteria}

Homofermentative LAB, including Lactobacillus species, such as $L$. delbrueckii subsp. bulgaricus, $L$. helveticus, $L$. kefiranofaciens subsp. kefiranofaciens, $L$. kefiranofaciens subsp. kefirgranum and L. acidophilus; Lactococcus spp. Such as L. lactis subsp. lactis and L. lactis subsp. cremoris and Streptococcus thermophilus have been identified in kefir grains and in the fermented beverage, as well as heterofermentative $\mathrm{LAB}$, including $L$. kefiri, $L$. parakefiri, L. fermentum and L. brevis (Leite et al., 2012; Rattray and O'Connel, 2011), and citrate-positive strains of L. lactis (L. lactis subsp. lactis biovar diacetylactis), Leuconostoc mesenteroides subsp. cremoris, and Leuconostoc mesenteroides subsp. mesenteroides (Leite et al., 2012; Lopitz-Otsoa et al., 2006; Rattray and O'Connel, 2011). The use of citrate by citrate-positive strains results in the production of key compounds that contribute to typical kefir flavour (Rattray and O'Connel, 2011).

Kefiran produced by $L$. kefiranofaciens is a branched, water-soluble polysaccharide, containing equal amounts of D-glucose and D-galactose. The production of this polysaccharide is stimulated when L. kefiranofaciens grows in co-culture with $S$. cerevisiae (Cheirsilp et al., 2003).

$\mathrm{AAB}$ species have been isolated and identified in both kefir grain and the kefir beverage. However, in some countries, the presence of these species is considered undesirable (Farnworth and Mainville, 2008; Rattray and O'Connel, 2011; Tamime, 2006) and has received less attention, even though they play an essential role in both the microbial consortium and the sensory characteristics of the final product (Rea et al., 1996; Tamime, 2006). 


\section{Kefir Yeast}

Although they produce metabolites that contribute to the desirable and typical kefir sensory properties (Rattray and O'Connel, 2011; Simova et al., 2002), kefir yeast are

A

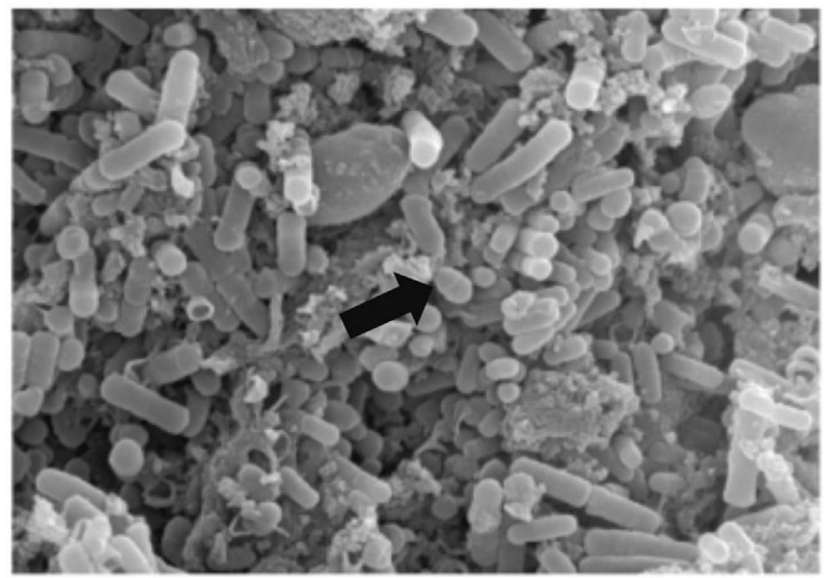

C

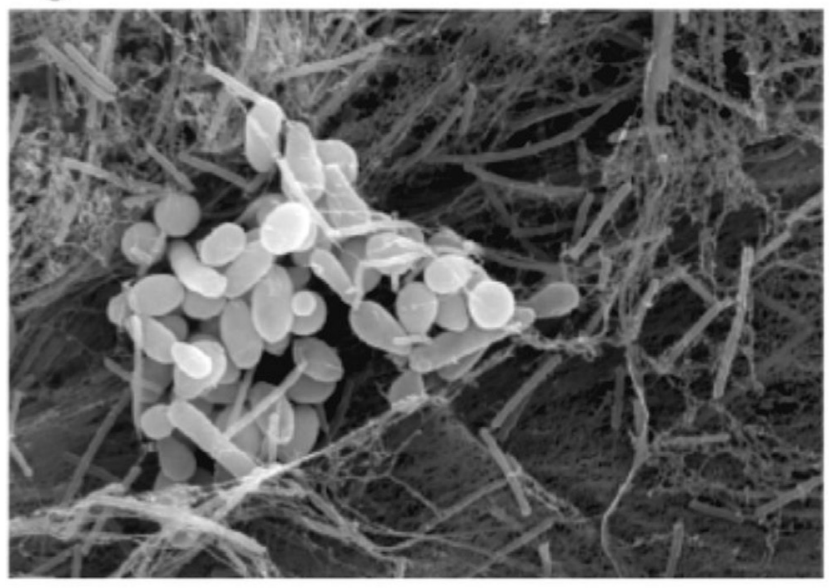

E

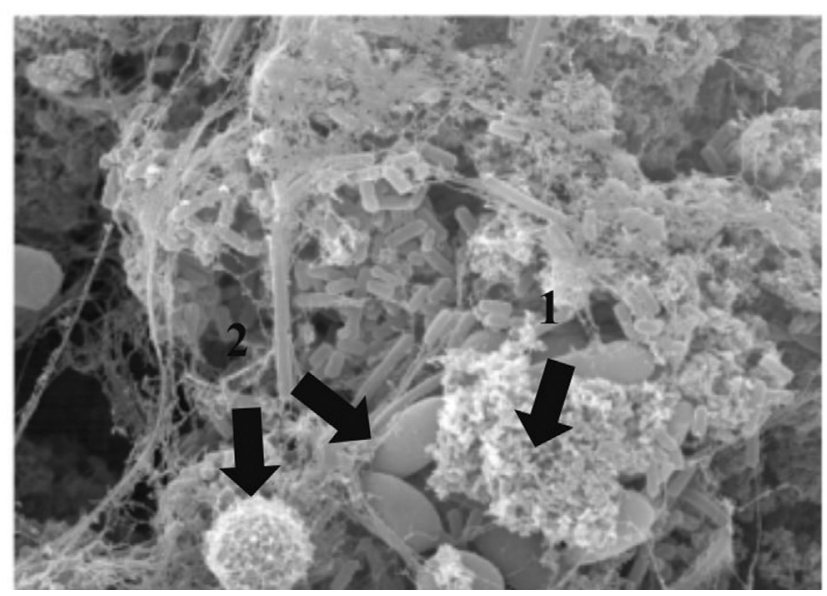

less studied than kefir bacteria. The main yeast capable of fermenting lactose found in kefir and kefir grains are Kluyveromyces marxianus/Candida kefyr, Kluyveromyces lactis var. lactis, Debaryomyces hansenii e Dekkera

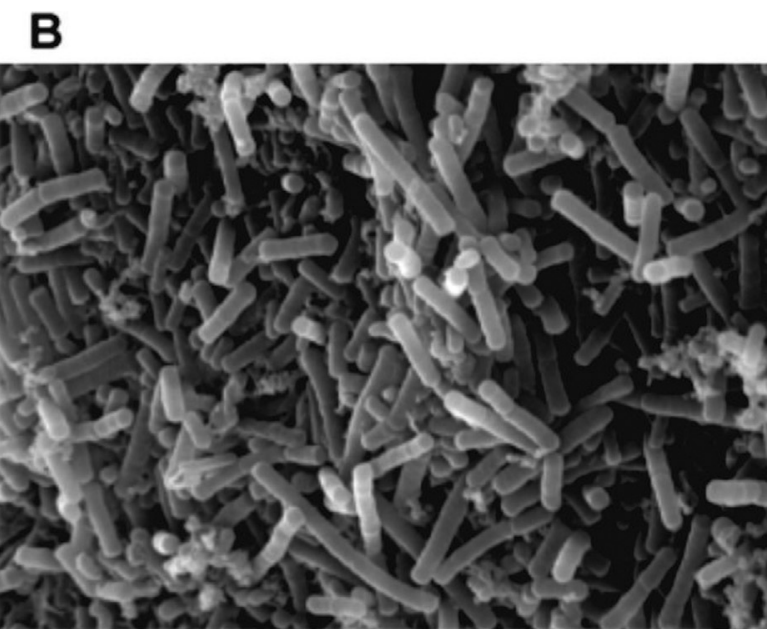

D

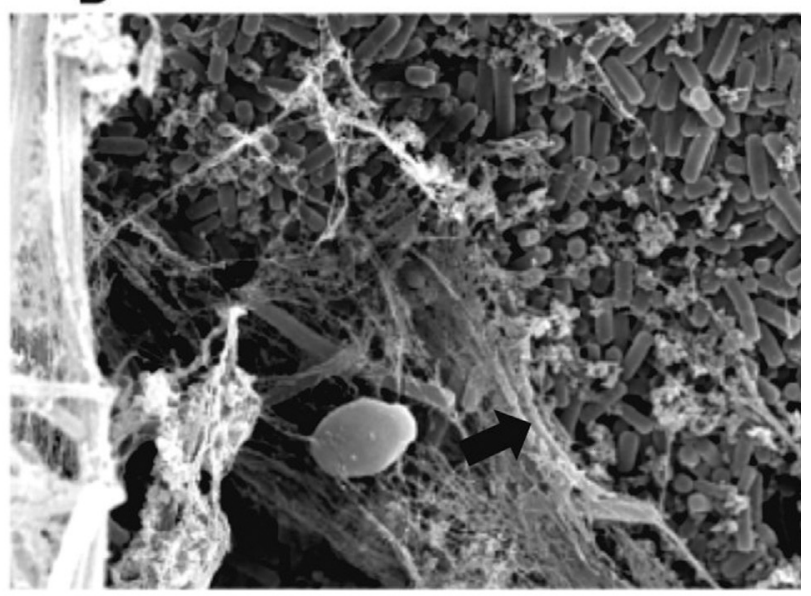

$\mathbf{F}$

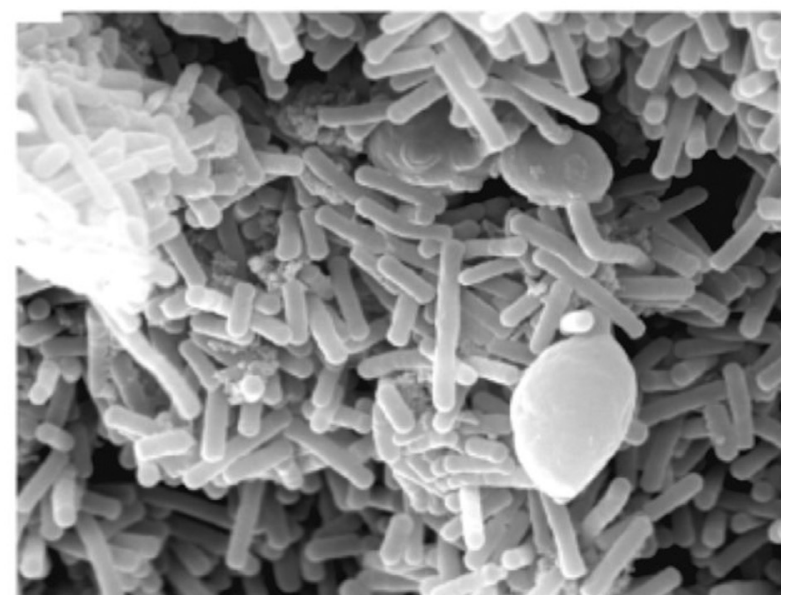

Figure 2 - Scanning electron microscopy of Brazilian kefir grain microbiota. A, C, E: outer grain portions, B, D, F: inner grain portions. Arrows Micrography A: cocci; Micrography D: fibrillar material - kefiran polysaccharide; Micrography E: arrow 1 - granular material - coagulated protein, arrow 2 - different yeast species. 
anomala, while the non-lactose fermenters include Saccharomyces cerevisiae, Torulaspora delbrueckii, Pichia fermentans, Kazachstania unispora, Saccharomyces turicensis, Issatchenkia orientalis and Debaryomyces occidentalis .

\section{Interactions between Kefir Microorganisms}

The complex interactions between yeast and bacteria and their interdependence in kefir grains are not completely understood. However, when the bacteria are separated from the grain, yeast will not grow as efficiently (Cheirsilp et al., 2003; Farnworth and Mainville, 2008; Rattray and O'Connel, 2011).

Due to its high capacity to metabolize lactose (Rea et al., 1996), the genus Lactococcus tends to grow faster than yeast in milk (Rea et al., 1996; Tamime, 2006). This genus hydrolyzes lactose, producing lactic acid and a suitable environment for yeast growth (Tamime, 2006). Moreover, yeasts synthesize complex B vitamins and hydrolyze milk proteins, using oxygen to produce $\mathrm{CO}_{2}$ and ethanol (Lopitz-Otsoa et al., 2006; Tamime, 2006). The interaction between yeast and lactic acid bacteria can be stimulated or inhibited by the growth of one or both, in co-cultures. These microorganisms can compete for nutrients for growth, or may produce metabolites that inhibit or stimulate one another (Lopitz-Otsoa et al., 2006). Some yeast species are proteolytic or lipolytic, providing amino acids and fatty acids (Rattray and O'Connel, 2011). Species such as Debaryomyces hansenii and Yarrowia lipolytica assimilate the lactic acid formed by $\mathrm{LAB}$, raising the $\mathrm{pH}$ and stimulating bacteria growth. The production of vitamin B by Acetobacter spp. also favors the growth of other microorganisms present in kefir grains (Lopitz-Otsoa et al., 2006; Rea et al., 1996).

\section{Technological Aspects}

During fermentation, the grains increase in size and number, and are usually recovered from the fermented milk and reutilized (Garrote et al., 2010). If carefully preserved, they may retain their activity for years (Lopitz-Otsoa et al., 2006; Rattray and O'Connel, 2011). The main marker to assess the symbiotic relationship between the different microorganisms is increased biomass during fermentation (Garrote et al., 2010).

\section{Grain Preservation}

Kefir grains can be preserved lyophilized, dry or wet (Garrote et al., 2010), but constant washing reduces their viability (Farnworth and Mainville, 2008). However, Pintado, et al. (1996) observed that grain stored in these conditions present different microbiological profiles than fresh grain. Dried grains maintain their activity for 12-18 months while wet grains maintain activity for 8-10 days (Garrote et al., 2010). Different preservation methods have been tested
(Garrote et al., 1997), with freezing being considered the best method. Grain lyophilization has also been tested, but resulted in reduced lactose metabolism, as well as modifications in the bacterial profile, which was different from the original grain profile (Farnworth and Mainville, 2008).

\section{Kefir Production}

There are three main ways of producing kefir (I) the artisanal process, (II) the commercial process by the Russian method and (III) the commercial process using pure cultures (Farnworth, 2005; Otles and Cagindi, 2003; Rattray and O'Connel, 2011). Other substrates may also be used, such as milk from other animal species, coconut milk, soybean milk, fruit juices and/or sugar and molasses solutions (Magalhães et al., 2010a; Öner et al., 2010; Rattray and O'Connel, 2011).

The traditional artisanal production involves milk inoculation with a variable amount of grains and fermentation for a period between $18-24 \mathrm{~h}$ at $20-25^{\circ} \mathrm{C}$. At the end of the fermentation process the grains are sieved and can be used for a new fermentation or kept (1-7 days) in fresh milk, while the kefir beverage is stored at $4{ }^{\circ} \mathrm{C}$, ready for consumption (Beshkova et al., 2002; Farnworth and Mainville, 2008; Otles and Cagindi, 2003).

The initial inoculum concentration of the grains (grain/milk proportion) affects the $\mathrm{pH}$, viscosity, final lactose concentration and the microbiological profile of the final product (Garrote et al., 1998; Simova et al., 2002). Agitation during fermentation also influences kefir microbial composition, favoring the development of homofermentative lactococci and yeast (Farnworth and Mainville, 2008; Rattray and O'Connel, 2011; Tamime, 2006). Incubation at temperatures above $30^{\circ} \mathrm{C}$ stimulates the growth of thermophilic $\mathrm{LAB}$, while being a disadvantage for yeast growth and mesophilic LAB (Rattray and O'Connel, 2011).

The second method, known as the "Russian method", allows for the production of kefir on a larger scale, and uses a process of fermentation in series, from the percolate resulting from the first fermentation of the grains (fermented without the grains or mother culture) (Farnworth and Mainville, 2008; Rattray and O'Connel, 2011).

Different methods can be used in the industrial process of kefir production, but all based on the same principle. The milk is inoculated with pure cultures isolated from kefir grains and commercial cultures (Beshkova et al., 2002; Rattray and O'Connel, 2011; Tamime, 2006). The maturation phase can be performed or not, consisting of maintaining the kefir at $8-10^{\circ} \mathrm{C}$ for up to $24 \mathrm{~h}$ (Beshkova et al., 2002; Rattray and O'Connel, 2011), to allow microorganism, primarily yeast, growth, contributing to the specific flavour of the product (Beshkova et al., 2002). Omission of this step is associated with development of atypical flavour in kefir (Beshkova et al., 2002; Rattray and O'Connel, 2011). 
During storage, the $\mathrm{CO}_{2}$ production by yeast or heterofermentative $\mathrm{LAB}$ can cause bloating in the product package, a fact that should be considered in the choice of packaging (Farnworth and Mainville, 2008; Sarkar, 2008).

Although the commercial beverage is available in many countries, not all the properties of traditional kefir are always present (Farnworth and Mainville, 2008; LopitzOtsoa et al., 2006). Assadi et al. (2000) tested several ratios of starter cultures isolated from the grains (LAB, yeast, $\mathrm{AAB}$ ), and found that traditional kefir produced with kefir grains has been better accepted than kefir obtained by using the starter culture. Rossi and Gobbetti (1991) produced a "kefir-type" beverage, with lower viscosity and the absence of some of the volatile components often found in traditional kefir. Carneiro (2010) on the other hand, developed a starter culture from microorganisms isolated from Kefir grains and the product was more accepted that the traditional kefir. Beshkova et al. (2002) proposed two methods of kefir fermentation: one by simultaneous fermentation and one by successive fermentation. Therefore, they used a starter culture consisting of bacteria and yeast isolated from kefir grains, combined to two strains commonly used in yogurt manufacturing. Yeasts were added to the starter culture with sucrose, both at the beginning (simultaneous fermentation) and after the lactic acid fermentation step (successive fermentation). The two fermentation processes produced kefir with high number of viable lactococci and lactobacilli, with sensory properties similar to traditional kefir.

The use of commercial cultures can standardize the commercial production of kefir, if the selection of species and strains of yeasts and bacteria is carried out accurately and carefully, thus allowing for the production of a "kefirtype" beverage with acceptable flavour and good conservation properties (Beshkova et al., 2002; Carneiro, 2010). The commercial beverage may have a commercial life period of up to 28 days, while it is recommended that kefir produced with grains be consumed between 3-12 days. However, the "kefir-type" beverage may not present the same therapeutic and probiotic properties present in traditional kefir (Rattray and O’Connel, 2011).

The development of a "kefir-type" beverage is not the only industrial application that has been investigated. Kefir grains have also been studied regarding the production of single cell protein (SCP) in the bioconversion of cheese whey and their application in the food industry, to improve the sensory characteristics of certain products (Paraskevopoulou et al., 2003).

The main deficiencies in kefir manufacturing can be attributed to unpleasant taste and aroma typical of yeast (Tamime, 2006). The latter can be caused by rapid growth of $S$. cerevisiae, accompanied by a typical vinegar aroma (Tamime, 2006). The excessive production of acetic acid can also influence kefir aroma, and occurs due to the intense growth of Acetobacter spp. or the presence of
Dekkera spp. in the grains. A bitter taste may be caused by fungi (for example Geotrichum candidum) and/or the activity of some atypical yeasts which may be present in the product (Tamime, 2006).

\section{Therapeutic Aspects}

Historically, kefir has been recommended for the treatment of several clinical conditions such as gastrointestinal problems, hypertension, allergies, and ischemic heart disease (Farnworth and Mainville, 2008; Rattray and O'Connel, 2011). However, the variability inherent in kefir production conditions in different assays makes it difficult to conduct comparisons between reported scientific results (Farnworth, 2005; Farnworth and Mainville, 2008; Rattray and O'Connel, 2011).

Kefir grain fermentations from various substrates have been evaluated (Farnworth, 2005; Magalhães et al., 2010a; Öner et al., 2010) and a wide variety of bioactive compounds have been observed, such as organic acids, $\mathrm{CO}_{2}, \mathrm{H}_{2} \mathrm{O}_{2}$, ethanol, bioactive peptides, exopolysaccharides (kefiran), and bacteriocins. These compounds may act independently or together to produce the various health benefits attributed to kefir consumption (Garrote et al., 2010; Rattray and O'Connel, 2011).

\section{Antimicrobial Activity}

Santos et al. (2003) observed the antagonistic behavior of lactobacilli isolated from kefir grains against E. coli, L. monocytogenes, Salmonella Typhimurium, $S$. Enteritidis, Shigella flexneri and Y. enterocolitica. Silva et al. (2009) observed the inhibition of Candida albicans, Salmonella Typhi, Shigella sonnei, Staphylococcus aureus and $E$. coli by kefir cultured in brown sugar. On the other hand, Chifiriuc et al. (2011) observed that all milk fermented with kefir grains had antimicrobial activity against Bacillus subtilis, S. aureus, E. coli, E. faecalis and $S$. Enteritidis, but did not inhibit $P$. aeruginosa and $C$. albicans. All these studies indicate that kefir antimicrobial activity is associated with the production of organic acids, peptides (bacteriocins), carbon dioxide, hydrogen peroxide, ethanol and diacetyl. These compounds may have beneficial effects not only in the reduction of food borne pathogens and deteriorating bacteria during beverage production and storage, but also in the treatment and prevention of gastroenteritis and vaginal infections (Farnworth, 2005; Sarkar, 2007). In addition, the antimicrobial activity of the polysaccharide kefiran was also demonstrated against bacteria and C. albicans (Rodrigues et al., 2005).

\section{Anti-inflammatory and Healing Activity}

Healing and anti-inflammatory activities of kefir and kefiran in mice were observed after a seven-day treatment with kefir gel (Rodrigues et al., 2005), as well as antiinflammatory activitiy (Diniz et al., 2003) on a model in 
which granulomatous tissue and writhing is induced by acetic acid in mice. Husseini et al. (2012) corroborated the healing activity in burns infected with Pseudomonas aeruginosa in mice.

\section{Impact on the Gastrointestinal Tract (GIT)}

The effect caused by kefir consumption in the intestinal microbiota composition may be due to a combination of factors, such as direct pathogen inhibition by acids and bacteriocin production, besides competitive pathogen exclusion in the intestinal mucosa (Rattray and O'Connel, 2011). According to Marquina et al. (2002) kefir consumption significantly increased LAB counts in the intestinal mucosa and reduced enterobacteria and clostridia populations. Furthermore, kefir consumption also prevented $C$. jejuni colonization in chick ceca (Zacconi et al., 2003), and was effective in postoperative treatments and in patients with gastrointestinal disorders (Sarkar, 2007). In Russia, kefir has been used by researchers in the treatment of peptic ulcers in the stomach and duodenum of human patients (Farnworth and Mainville, 2008).

\section{Anticarcinogenic Effects}

The anticarcinogenic role of fermented dairy products can be attributed, in general, to cancer prevention and the suppression of early-stage tumors, by the delaying of enzyme activities that convert pro-carcinogenic compounds to carcinogens, or by the activation of the immune system (Sarkar, 2007). Kubo et al. (1992) reported the inhibition of the proliferation of subcutaneously transplanted Ehrlich ascites tumors in mice. Liu et al. (2002) observed the inhibition of tumor growth, the induction of apoptotic cell lysis in tumors and significant increases in IgA levels in mice, suggesting that kefir potentially has anti-tumoral properties and promotes resistance of the mucosa to intestinal infections. Guven and Gulmez (2003) reported that mice treated with kefir had a higher protective effect against damage induced by carbon tetrachloride, indicating that kefir can also act as an antioxidant.

\section{Stimulation of the Immune System}

The formation of bioactive peptides during fermentation or digestion processes has shown a variety of physiological activities, including stimulation of the immune system in animal models (Farnworth, 2005). Thoreux and Schmucker (2001), after feeding mice with kefir, observed an increase in the specific mucosal immune response (IgA) against the cholera toxin. Stimulation of the immune system may also occur due to the action of exopolysaccharides found in kefir grains (Farnworth, 2005; Furukawa et al., 1992). Medrano et al. (2011) observed that kefiran was able to modify the balance of the immune cells in the intestinal mucosa. Vinderola et al. (2005) demonstrated the immunomodulation ability of kefir in the immune response of the intestinal mucosa of mice. The administration of kefir also induced a response in the intestinal mucosa, suggesting that components of kefir can stimulate cells of the innate immune system, suppressing the immune response of the Th2 phenotype or promoting cell-mediated immune responses against tumors and intracellular pathogen infections (Liu et al., 2002). Recently, Hong et al. (2009) demonstrated, in vitro, the immunomodulating capacity of LAB isolated from kefir grains, suggesting their influence on the secretion of the proinflammatory cytokines IL- 6 and TNF- $\alpha$ by TLR- 2 .

\section{Hypocholesterolemic Effect}

Possible mechanisms proposed for the hypocholesterolemic activity in LAB may involve the inhibition of the exogenous cholesterol absorption in the small intestine, by the binding and incorporation of cholesterol to bacterial cells and cholesterol uptake, as well as suppression of bile acid reabsorption by enzymatic deconjugation of bile salts, promoted by the bile salt hydrolase (BSH) enzyme (Wang et al., 2009). Wang et al. (2009) observed a significant reduction in serum levels of total cholesterol, low density lipoproteins (LDL) and triglycerides, while there was no change in high density lipoprotein (HDL-C) levels in mice fed cholesterol-rich a diet supplemented with Lactobacillus plantarum MA2. Moreover, total cholesterol and triglycerides in the liver were also reduced. Cholesterol and triglycerides in animal feces, on the other hand, increased significantly. Another study (Liu et al., 2006) also observed a reduction of serum triglyceride and cholesterol levels, especially the non-HDL-C fraction. A contradictory result was reported by St-Onge et al. (2002), where kefir consumption did not reduce total cholesterol, LDL-C, HDL-C and triglycerides levels, but increased the concentrations of isobutiric, propionic and isovaleric acids, as well as the total amount of short chained fatty acids in faeces.

\section{Kefir and Lactose Intolerance}

The ability to decrease lactose concentrations and the presence of $\beta$-galactosidase activity in fermented milk products make them suitable for consumption by people classified as lactose intolerant (Farnworth and Mainville, 2008; Sarkar, 2007). It has been demonstrated that some kefir grains show $\beta$-galactosidase enzyme activity, which stays active when consumed, and that kefir contains less lactose than milk (Farnworth, 2005; Sarkar, 2007). A commercial kefir (Hertzler and Clancy, 2003) proved to be as effective as yoghurt in reducing expired hydrogen and flatulence in lactose intolerant adults when compared to the ingestion of milk. de Vrese et al. (1992) demonstrated that pigs fed with kefir showed a significant increase in galactose plasma concentrations, suggesting improvement of intestinal lactose hydrolysis by the microbial enzyme $\beta$-galactosidase. 


\section{Final Considerations}

Kefir is a traditional example of the co-existence of bacteria and yeasts and the importance of this symbiotic relationship seems clear, since it is necessary to produce compounds beneficial to health. Although the evidence is not conclusive and further studies should be conducted, the existing scientific studies demonstrate the health benefits reported empirically by historical kefir consumption. Currently, the application of probiotics in the food industry is in expansion and understanding the symbiotic relationships between different microorganisms present in food, as well as their interactions, could assist in the improvement of technological processes.

The quality of traditional kefir is mainly influenced by the microorganisms present in kefir grains and kefir processing conditions. Although scientists and food companies attempted to develop a commercial "kefir-type" beverage produced by different cultures and mesophilic and thermophilic LAB, or even pure cultures isolated from kefir grains, their success when compared to traditional kefir is limited. We suggest that this limitation is due to the microbial diversity present in kefir grains and their interactions, which can determine the probiotic and therapeutic properties of final product, as well as peculiarities conferred by certain minority groups present in different grains. However, from an industrial point of view, these developments are welcome, given the lack of standardization in the production and marketing of traditional kefir.

\section{Acknowledgments}

The authors acknowledge the help of Prof. Dr. Sergio Seabra and lab technician Eliandro Lima State of the Universidade Estadual da Zona Oeste (UEZO) and M.Sc. Laidson Paes Gomes for technical assistance in the sample processing and SEM micrographs. We also thank to Conselho Nacional de Desenvolvimento Científico e Tecnológico (CNPq), Fundação de Amparo à Pesquisa do Estado do Rio de Janeiro (FAPERJ) and Coordenação de Aperfeiçoamento de Pessoal de Nível Superior (CAPES).

\section{References}

Assadi MM, Pourahmad R, Moazami N (2000) Use of isolated kefir starter cultures in kefir production. World J Microbiol Biotechnol 16:541-543.

Beshkova D, Simova ED, Simov ZI, Frengova GI, Spasov Z N (2002) Pure cultures for making kefir. Food Microbiol 19:537-544.

Bottazzi V, Bianchi F (1980) A Note on Scanning Electron Microscopy of Micro-organisms associated with the Kefir Granule. J Appl Microbiol 48:265-268.

Carneiro RP (2010) Desenvolvimento de uma cultura iniciadora para produção de kefir. Belo Horizonte, Brasil, p.142. (M.Sc. Dissertation. Faculdade de Farmácia. UFMG).
Cheirsilp B, Shimizu H, Shioya S (2003) Enhanced kefiran production by mixed culture of Lactobacillus kefiranofaciens and Saccharomyces cerevisiae. J. Biotechnol 100:43-53.

Chifiriuc MC, Cioaca AB, Lazar V (2011) In vitro assay of the antimicrobial activity of kephir against bacterial and fungal strains. Anaerobe 17:433-435.

de Vrese M, Keller B, Barth CA (1992) Enhancement of intestinal hydrolysis of lactose by microbial beta-galactosidase (EC 3.2.1.23) of kefir. Br J Nutr 67:67-75.

Diniz RO, Perazzo FF, Carvalho JCT, Schneenedorf JM (2003) Atividade antiinflamatória de quefir, um probiótico da medicina popular. Rev Bras Farmacogn 13:19-21.

Dobson A, O'Sullivan O, Cotter PD, Ross P, Hill C (2011) High-throughput sequence-based analysis of the bacterial composition of kefir and an associated kefir grain. FEMS Microbiol Lett 320:56-62.

Farnworth ER (2005) Kefir - a complex probiotic. Food Sci Technol Bull: Functional Foods 2:1-17.

Farnworth ER, Mainville I (2008) Kefir - A Fermented Milk Product. In: Farnworth, E. R. ( $2^{\text {th }}$ ed.), Handbook of Fermented Functional Foods (2 ed). CRC Press Taylor \& Francis Group, Boca Raton, London, New York, p. 89-127.

Furukawa N, Liyama R, Takahashi T, Yamanka Y (1992) The effect of oral administration of water soluble fraction from kefir grain on antibody production in mice. Anim Sci Technol 63:428-436.

Garrote GL, Abraham AG, De Antoni G (1997) Preservation of Kefir Grains, a Comparative Study. Lebensm-Wiss u-Technol 30:77-84.

Garrote GL, Abraham AG, De Antoni G (1998) Characteristics of kefir prepared with different grain:milk ratios. J Dairy Res 65:149-154.

Garrote GL, Abraham AG, De Antoni G (2010) Microbial Interactions in Kefir: A Natural Probiotic Drink. In F. Mozzi, R. R. Raya \& G. M. Vignolo (Eds.), Biotechnology of Lactic Acid Bacteria - Novel Applications pp. 327-340. Iowa: Blackwell Publishing.

Guven A, Gulmez M (2003) The effect of kefir on the activities of GSH-Px, GST, CAT, GSH and LPO levels in carbon tetrachloride-induced mice tissues. J Vet Med B Infect Dis Vet Public Health 50:412-416.

Guzel-Seydim Z, Wyffels JT, Seydim AC, Greene AK (2005) Turkish kefir and kefir grains: microbial enumeration and electron microscobic observation. Int J Dairy Technol 58:25-29.

Hertzler SR, Clancy SM (2003) Kefir improves lactose digestion and tolerance in adults with lactose maldigestion. J Am Diet Assoc 103:582-587.

Hong WS, Chen HC, Chen YP, Chen MJ (2009) Effects of kefir supernatant and lactic acid bacteria isolated from kefir grain on cytokine production by macrophage. Int Dairy J 19:244251.

Huseini HF, Rahimzadeh G, Fazeli MR, Mehrazma M, Salehi M (2012) Evaluation of wound healing activities of kefir products. Burns 38:719-723.

Jianzhong Z, Liu X, Jiang H, Dong M (2009) Analysis of the microflora in Tibetan kefir grains using denaturing gradient gel electrophoresis. Food Microbiol 26:770-775.

Kubo M, Odani T, Nakamura S, Tokumaru S, Matsuda H (1992) Pharmacological study on kefir - a fermented milk product 
in Caucasus. I. On antitumor activity. Yakugaku Zasshi 112:489-495.

Leite AMO, Mayo B, Rachid CTCC, Peixoto RS, Silva JT, Paschoalin VMF, Delgado S (2012) Assessment of the microbial diversity of Brazilian kefir grains by PCR-DGGE and pyrosequencing analysis. Food Microbiol 31:215-221.

Lin CW, Chen HL, Liu JR (1999) Identification and characterization of lactic acid bacteria and yeasts isolated from kefir grains in Taiwann. Aust Journal of Dairy Tech 54:14-18.

Liu JR, Wang SY, Chen MJ, Chen HL, Yueh PY, Lin CW (2006) Hypocholesterolaemic effects of milk-kefir and soyamilkkefir in cholesterol-fed hamsters. Br J Nutr 95:939-946.

Liu JR, Wang SY, Lin YY, Lin CW (2002) Antitumor activity of milk kefir and soy milk kefir in tumor-bearing mice. Nutr Cancer 44:183-187.

Lopitz-Otsoa F, Rementeria A, Elguezabal N, Garaizar J (2006) Kefir: a symbiotic yeasts-bacteria community with alleged healthy capabilities. Rev Iberoam Micol 23:67-74.

Magalhães KT, Pereira GVM, Campos CR, Dragone G, Schwan RF (2011) Brazilian Kefir: Structure, Microbial Communities and Chemical Composition. Braz J Microbiol 42:693-702.

Magalhães KT, Pereira GVM, Dias DR, Schwan RF (2010a) Microbial communities and chemical changes during fermentation of sugary Brazilian kefir. World J Microbiol Biotechnol 26:1241-1250.

Magalhães KT, Pereira MA, Nicolau A, Dragone G, Domingues L, Teixeira JA, Silva JBA, Schwan RF (2010b) Production of fermented cheese whey-based beverage using kefir grains as starter culture: Evaluation of morphological and microbial variations. Bioresour Technol 101:8843-8850.

Mainville I, Robert N, Lee B, Farnworth ER (2006) Polyphasic characterization of the lactic acid bacteria in kefir. Syst Appl Microbiol 29:59-68.

Marquina D, Santos A, Corpas I, Munoz J, Zazo J, Peinado JM (2002) Dietary influence of kefir on microbial activities in the mouse bowel. Lett Appl Microbiol 35:136-140.

Medrano M, Racedo SM, Rolny IS, Abraham A a G, Perez PF (2011) Oral Administration of Kefiran Induces Changes in the Balance of Immune Cells in a Murine Model. J Agric Food Chem 59:5299-5304.

Öner Z, Karahan AG, Çakmakçi MLE (2010) Effects of different milk types and starter cultures on kefir. Gida 35:177-182.

Otles S, Cagindi O (2003) Kefir: A probiotic dairy-composition, nutritional and therapeutic aspects. Pakistan J Nutr 2:54-59.

Paraskevopoulou A, Athanasiadis I, Kanellaki M, Bekatorou A, Blekas G, Kiosseoglou V (2003) Functional properties of single cell protein produced by kefir microflora. Food Res Int 36:431-438.

Pintado ME, Da Silva JAL, Fernandes PB, Malcata FX, Hogg TA (1996) Microbiological and rheological studies on Portuguese kefir grains. Int J Food Sci Technol 31:15-26.

Rattray FP, O'Connell MJ (2011) Fermented Milks Kefir. In: Fukay, J. W. (ed.), Encyclopedia of Dairy Sciences $\left(2^{\text {th }} \mathrm{ed}\right)$. Academic Press, San Diego, USA, p.518-524.
Rea MC, Lennartsson T, Dillon P, Drina FD, Reville WJ, Heapes M, Cogan TM (1996) Irish kefir-like grains : their structure, microbial composition and fermentation kinetics. J Appl Microbiol 8:83-94.

Rodrigues KL, Caputo LR, Carvalho JC, Evangelista J, Schneedorf JM (2005) Antimicrobial and healing activity of kefir and kefiran extract. Int J Antimicrob Agents 25:404-408.

Rossi J, Gobbetti M (1991) Impiego di un multistarter per la produzione in continuo di kefir (Vol. 41). Milano, ITALIE: Dipartimento di scienze e tecnologie alimentari e microbiologiche dell' Universitá degli studi di Milano.

Santos A, San Mauro M, Sanchez A, Torres JM, Marquina D (2003) The Antimicrobial Properties of Different Strains of Lactobacillus spp. Isolated from Kefir. Syst Appl Microbiol 26:434-437.

Sarkar S (2007) Potential of kefir as a dietetic beverage - a review. Br Food J 109:280-290.

Sarkar S (2008) Biotechnological innovations in kefir production: a review. Br. Food J 110:283-295.

Silva KR, Rodrigues SA, Filho LX, Lima AS (2009) Antimicrobial activity of broth fermented with kefir grains. Appl Biochem Biotechnol 152:316-325.

Simova E, Beshkova D, Angelov A, Hristozova T, Frengova G, Spasov Z (2002) Lactic acid bacteria and yeasts in kefir grains and kefir made from them. J Ind Microbiol Biotechnol 28:1-6.

St-Onge MP, Farnworth E, Savard T, Chabot D, Mafu A, Jones P (2002) Kefir consumption does not alter plasma lipid levels or cholesterol fractional synthesis rates relative to milk in hyperlipidemic men: a randomized controlled trial. BMC Complement Altern Med 2:1.

Tamime AY (2006) Production of Kefir, Koumiss and Other Related Products. In: Tamime, AY (ed.), Fermented Milk Blackwell Science Ltd, Oxford, UK, p.174-216.

Thoreux K, Schmucker DL (2001) Kefir milk enhances intestinal immunity in young but not old rats. J Nutr 131:807-812.

Vinderola CG, Duarte J, Thangavel D, Perdigon G, Farnworth E, Matar C (2005) Immunomodulating capacity of kefir. J Dairy Res 72:195-202.

Vinderola G, Perdigon G, Duarte J, Thangavel D, Farnworth E, Matar C (2006) Effects of kefir fractions on innate immunity. Immunobiology 211:149-156.

Wang Y, Xu N, Xi A, Ahmed Z, Zhang B, Bai X (2009) Effects of Lactobacillus plantarum MA2 isolated from Tibet kefir on lipid metabolism and intestinal microflora of rats fed on high-cholesterol diet. Appl Microbiol Biotechnol 84:341347.

Zacconi C, Scolari G, Vescovo M, Sarra PG (2003) Competitive exclusion of Campyloacter jejuni by kefir fermented milk. Ann Microbiol 53:179-187.

All the content of the journal, except where otherwise noted, is licensed under a Creative Commons License CC BY-NC. 